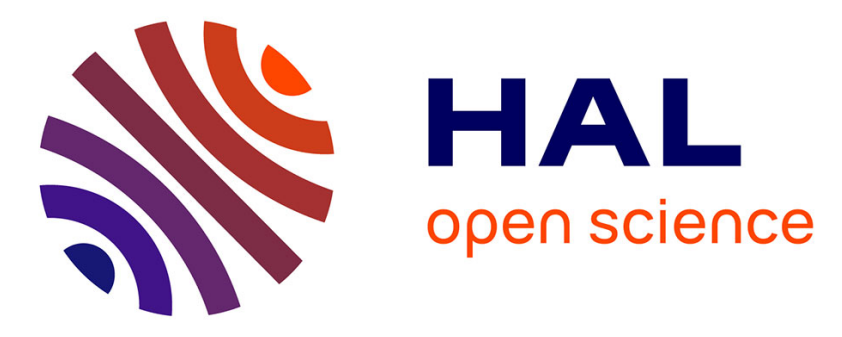

\title{
Diagnosis of sensor grids in a building system using BRIDGE approach
}

\author{
Houda Najeh, Mahendra Pratap Singh, Karim Chabir, Stéphane Ploix, \\ Mohamed Naceur Abdelkrim
}

\section{- To cite this version:}

Houda Najeh, Mahendra Pratap Singh, Karim Chabir, Stéphane Ploix, Mohamed Naceur Abdelkrim. Diagnosis of sensor grids in a building system using BRIDGE approach. 18th international conference on Sciences and Techniques of Automatic control \& STA'2017-PID4533-SGPS computer engineering - STA'2017, Dec 2017, Monastir, Tunisia. hal-01917072

\section{HAL Id: hal-01917072 https://hal.science/hal-01917072}

Submitted on 19 Nov 2018

HAL is a multi-disciplinary open access archive for the deposit and dissemination of scientific research documents, whether they are published or not. The documents may come from teaching and research institutions in France or abroad, or from public or private research centers.
L'archive ouverte pluridisciplinaire HAL, est destinée au dépôt et à la diffusion de documents scientifiques de niveau recherche, publiés ou non, émanant des établissements d'enseignement et de recherche français ou étrangers, des laboratoires publics ou privés. 


\title{
Diagnosis of sensor grids in a building system using BRIDGE approach
}

\author{
Houda NAJEH*, Mahendra Pratap SINGH ${ }^{\dagger}$, Karim CHABIR* ${ }^{*}$ Stéphane PLOIX ${ }^{\dagger}$ and \\ Mohamed Naceur ABDELKRIM* \\ *University of Gabes, National Engineering School of Gabes, Tunisia \\ Research lab. Modeling, Analysis and Control of Systems (MACS) LR16ES22 \\ ${ }^{\dagger}$ University of Grenoble Alpes, G-SCOP lab, CNRS UMR 5272, Grenoble, France \\ najehhoudaenig@gmail.com \\ talk2mpsingh@gmail.com \\ stephane.ploix@grenoble-inp.fr \\ karim.chabir@yahoo.fr \\ naceur.abdelkrim@laposte.net
}

\begin{abstract}
This paper aims at designing a diagnosis tool for detecting and localizing faults in a building system. A Bridge approach based diagnostic reasoning is used because it proves to be more relevant to provide the possible fault modes including multiple sensor faults. The efficiency of this method is illustrated by an example.
\end{abstract}

Index Terms - BRIDGE approach, sensor grids, test design, fault diagnosis, building system

\section{INTRODUCTION}

Performing diagnoses count on a complex process, which is decomposed in 2 steps: a design process and a running process. The following design tasks may be distinguished: system modeling, sensor placement, detection test design and isolation algorithm design. The system modeling task aims at formalizing the reference behaviors. In general, reference behaviors are modeled by constraints that establish the relation ships between data coming from observations and unknown variables. Each constraint models one or several behavioral modes. In AI community, a system modeling task is detailed in [2] and [12]. Each system's element can take 2 modes: the ok mode, denoted ok(component) in [5], which represent the normal behavior of a component and its complementary mode, named unknown fault mode in [5], [13]. It's named cfm(component). Modeling task is to formalize the constraints that model the different modes of the system to be diagnosed.

The design of detection tests is usually not explicit in AI approaches: Tests are always designed by checking the consistence between the constraints and the data. But, FDI community's results ([1], [4]) indicate that a detection test can not be given from a simple comparaison between the system description's element and observations. Thus, get together the works of FDI and AI community has been made in order to make a bridge between FDI and AI results ([3], [10]). As a result, detection test design tasks can be decomposed in to the two following sub tasks: the generation of testable subsystem and the detection algorithm: the first one selects subsets of constraints that may lead to detection tests[1], the second one consists in designing a detection test, often named Analytical Redundancy Relation, corresponding to each testable subset of constraints.

The task of designing isolation algorithm consists in selecting the most relevant diagnostic analysis approach. In order to analyse the symptoms generated by detection tests, different approaches like decision tree based approach $([9],[11])$, case based reasoning approach ([6], [8]) or the signature based approach [1] are proposed in the litterature. In this work, we consider the bridge approach [10]. It has been proved that we can use consistency based reasoning to analyze symptoms coming from detection tests characterized by the involved modes.

The paper focuses on a real case of study: an office in Grenoble Institute of Technology, where 3 persons work. It is equipped with 27 sensors which collect information about CO2 concentration, temperature, occupancy ... In addition, it is also equipped with 2 cameras to verify the actions and routines of occupants. Fig.1 show the test bench.

This paper is organized as follow: section 2 presents the problem statement. In section 3, the physical model of the office is exposed. Section 4 is devoted to the design of tests. To assess the validity of the proposed approach, experimental validation is presented in section 5. Finally, concluding remarks are given in section 6 . 


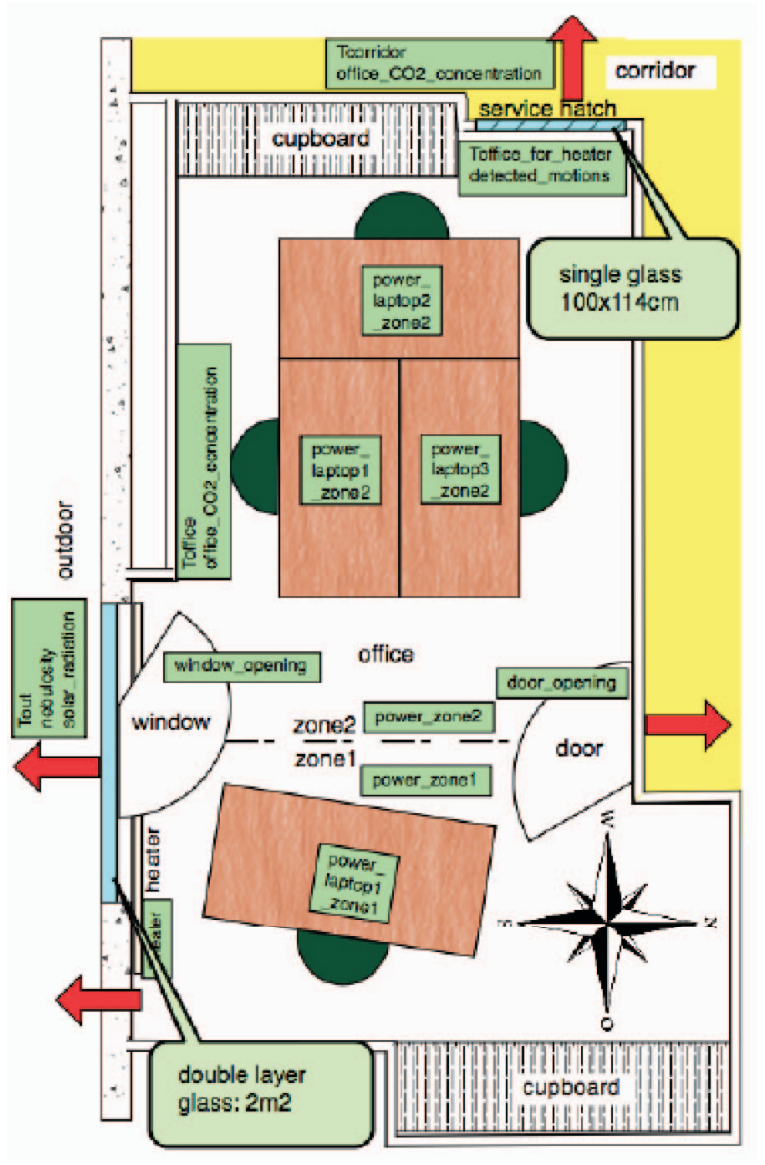

Fig. 1: Test bench

\section{Problem Statement}

\section{A. Design of detection tests}

The design of detection tests is the first step of a diagnostic process. Detection tests are designed to reveal the faulty behavior in the sensor grids. They are derived from simple sensor measurements and uses the method of bound check to decide whether a subsystem is faulty or not. Bridge diagnosis process starts with a negative test. Using this approach, we analyse an office with about 30 sensors to determine whether the sensor has normal behavior or not. Each sensor represents the normal behavior and abnormality leads at least to one fault. The proposed approach focuses on performing detection tests to data sets and find the fault modes (ok(sensor 1$), \ldots$, ok(sensor $n)$ ) by applying the new approach to diagnosis.

\section{B. Symptom generation}

The symptom generation is the second task of a diagnostic process. Symptoms are generated thanks to a threshold of residuals.

The value of threshold is related to the distance between two sensors involved in the test. Thus, residual value is the hourly average value of the difference between the amount of data collected from two sensors. If the value of the residue is higher than the given threshold value, a symptom is generated.

The behavior of the building is dependent of the season, a period of validation from May 1st, 2015 to June 30th, 2015 is chosen.

\section{PHYSICAL MODEL}

Advanced energy management systems rely on physical models. For example, to predict the inside temperature for the office, the following physical model is used:

TABLE I: Physical parameters

\begin{tabular}{|c|c|}
\hline Parameter & Designation \\
\hline$T_{n}$ & the temperature of the neighbor corridor \\
\hline$T_{i n}$ & the temperature of the office \\
\hline$T_{\text {out }}$ & the outdoor temperature \\
\hline$R_{n}$ & the thermal resistances of the wall separating \\
the office from the corridor
\end{tabular}

$$
\text { Let } \begin{aligned}
\frac{1}{R}=\frac{1}{R_{i}}+\frac{1}{R_{\text {out }}}+\frac{\zeta_{W}}{R_{W}}+\frac{\zeta_{D}}{R_{D}}+\frac{1}{R_{n}} \\
R_{D}=\frac{1}{\rho_{\text {air }} C_{p, a i r} Q_{D}} \\
R_{W}=\frac{1}{\rho_{\text {air }} C_{p, a i r} Q_{W}}
\end{aligned}
$$

$$
\begin{aligned}
& \text { ok }(\mathrm{room}) \rightarrow \frac{d \tau}{d t}=\frac{R-R_{i}}{R_{i}^{2} C_{i}} \tau+\frac{R}{R_{i} C_{i}} \phi_{\text {in }} \\
&+\frac{R}{R_{i} C_{i}}\left(\frac{1}{R_{\text {out }}}+\frac{\zeta_{w}}{R_{w}}\right) T_{\text {out }}+\frac{R}{R_{i} C_{i}}\left(\frac{1}{R_{n}}+\frac{\zeta_{D}}{R_{D}}\right) T_{n} \\
& \begin{aligned}
\text { ok }(\mathrm{room}) \rightarrow T_{\text {in }} & =\frac{R}{R_{i}} \tau+R_{i} \phi_{\text {in }}+R\left(\frac{1}{R_{\text {out }}}+\frac{\zeta_{w}}{R_{w}}\right) T_{\text {out }} \\
& +R\left(\frac{1}{R_{n}}+\frac{\zeta_{D}}{R_{D}}\right) T_{n}
\end{aligned}
\end{aligned}
$$

with $R_{n}, R_{\text {out }}, R_{i}$ and $C_{i}$ time invariant.

Equation (4) constitute a model for predicting the inside temperature. By observing the variables included in it, we can conclude that the indoor temperature depend on different phenomena like the different sources of heat inside the office, corridor and outdoor temperatures etc... Determining the air quality is usually done by measuring the CO2 concentration in the air. Eq. (5) shows the model of the air quality. 
$C_{\text {out }}, C_{\text {cor }}$ and $C_{\text {in }}$ represent respectively the $\mathrm{CO}_{2}$ concentration of the outdoor, the corridor and the office. $V$ and $n$ represent respectively the volume of the office and the number of occupants.

$$
\begin{aligned}
V \frac{d C_{\text {in }}(t)}{d t}=-\left(Q_{\text {out }}(\right. & \left.t)+Q_{\text {cor }}(t)\right) C_{\text {in }}(t)+Q_{\text {out }}(t) C_{\text {out }} \\
+ & Q_{\text {cor }}(t) C_{c o r}(t)+S_{C O 2} n(t)
\end{aligned}
$$

$[7]$

with

$$
\begin{gathered}
Q_{\text {out }}(t)=Q_{0}^{\text {out }}(t)+\zeta_{W}(t) Q_{W} \\
Q_{\text {cor }}(t)=Q_{0}^{\text {cor }}(t)+\zeta_{D}(t) Q_{D}
\end{gathered}
$$

Then, it yields Eq. (8):

$$
\begin{gathered}
o k(\text { room }) \rightarrow V \frac{d C_{i n}(t)}{d t}=-\left(Q_{0}^{\text {out }}+Q_{0}^{\text {cor }} \zeta_{W}(t) Q_{W}\right. \\
\left.+\zeta_{D}(t) Q_{D}\right) C_{i n}(t)+\left(Q_{0}^{\text {out }}+\zeta_{W}(t) Q_{W}\right) C_{\text {out }} \\
+\left(Q_{0}^{\text {cor }}+\zeta_{D}(t) Q_{D}-\zeta_{W}(t) \zeta_{D}(t) Q_{W D}\right) C_{c o r}(t)+S_{C O_{2}} n(t)
\end{gathered}
$$

Sensors are modeled by a model which assumes that the actual value is equal to the measured value under the assumption that the sensor is working well.

Equations from Eq. (9) to Eq. (16) each represent the model for each sensor in the office.

$$
\begin{aligned}
& o k(\text { office_reference_temperature_sensor }) \\
& \rightarrow \tilde{T}_{\text {office_reference }}=T_{\text {_office_reference }}
\end{aligned}
$$

$$
\begin{aligned}
\text { ok }(\text { office_wall_temperature_sensor }) \\
\\
\rightarrow \tilde{T}_{\text {office_wall }}=\mathrm{T}_{\text {_office_wall }}
\end{aligned}
$$

$$
\begin{aligned}
& o k(\text { heater_temperature_sensor }) \\
& \quad \rightarrow \tilde{T}_{\text {heater }}=\mathrm{T}_{\text {_heater }}
\end{aligned}
$$

ok(corridor_temperature_sensor)

$$
\rightarrow \tilde{T}_{\text {corridor }}=\mathrm{T}_{-} \text {corridor }
$$

$o k\left(\mathrm{CO}_{2}\right.$ _concentration_sensor $) \rightarrow \tilde{C O}_{2}=\mathrm{CO}_{2}$

$$
\begin{array}{r}
o k\left(\text { corridor_CO } \mathrm{O}_{2} \text { cencentration_sensor }\right) \\
\rightarrow \tilde{C}_{\text {corridor }}=\mathrm{C}_{-} \text {corridor } \\
\text { ok(door_contact_sensor }) \rightarrow \tilde{\zeta_{D}}=\zeta_{D} \\
o k(\text { window_contact_sensor }) \rightarrow \tilde{\zeta_{W}}=\zeta_{W} \\
o k(\text { occupancy_sensor }) \rightarrow \text { occupancy }=\text { occupancy }
\end{array}
$$

Note that the symbol ${ }^{\sim}$ is used to denote the measured value and ok(component) signifies normal behavior of the component.

\section{Design of tests}

The following tests have been constitued in the framework of the office setting.

Test1 - check the performance of Toffice-reference and Theater sensors

ok (Toffice_reference_sensor $) \rightarrow$ Toffice $=$ Toffice-reference

ok (Theater_sensor) $\rightarrow$ Toffice $=\tilde{T}$ Theater

Test2 - check the performance of Toffice-wall and Toffice-reference sensors

ok (Toffice_wall_sensor) $\rightarrow$ Toffice $=$ Toffice-wall

ok (Toffice_reference_sensor) $\rightarrow$ Toffice $=$ Toffice-reference

Test3 - check the performance of door-contact sensor, window-contact sensor, Toffice-reference sensor and the validity of the model (ok(room)) ok (Toffice_reference_sensor) $\rightarrow$ Toffice $=\tilde{T}$ office-reference ok (door_contact_sensor) $\rightarrow \zeta_{D}=\tilde{\zeta}_{D}$

ok (window_contact_sensor) $\rightarrow \zeta_{W}=\tilde{\zeta}_{W}$

$\mathrm{ok}(\mathrm{room}) \rightarrow \frac{d \tau}{d t}=\frac{R-R_{i}}{R_{i}^{2} C_{i}}+\frac{R}{R_{i} C_{i}} \phi_{\text {in }}+\frac{R}{R_{i} C_{i}}\left(\frac{1}{R_{\text {out }}}+\right.$ $\left.\frac{\zeta_{w}}{R_{w}}\right) T_{\text {out }}+\frac{R}{R_{i} C_{i}}\left(\frac{1}{R_{n}}+\frac{\zeta_{D}^{2}}{R_{D}}\right) T_{n}$

$\mathrm{ok}(\mathrm{room}) \rightarrow T_{\text {in }}=\frac{R}{R_{i}} \tau+R_{i} \phi_{\text {in }}+R\left(\frac{1}{R_{\text {out }}}+\frac{\zeta_{w}}{R_{w}}\right) T_{\text {out }}+$ $R\left(\frac{1}{R_{n}}+\frac{\zeta_{D}}{R_{D}}\right) T_{n}$

Test4 - check the performance of Toffice-wall and Theater sensors

ok (Toffice_wall_sensor $) \rightarrow$ Toffice $=$ Toffice-wall

ok (Theater_sensor) $\rightarrow$ Toffice $=\tilde{T}$ heater

Test5 - check the performance of door-contact sensor, window-contact sensor, Theater sensor and the validity of the model (ok(room))

ok (Theater_sensor) $\rightarrow$ Toffice $=\tilde{T}$ heater

ok (door_contact_sensor) $\rightarrow \zeta_{D}=\tilde{\zeta}_{D}$

ok (window_contact_sensor) $\rightarrow \zeta_{W}=\tilde{\zeta}_{W}$

$\mathrm{ok}(\mathrm{room}) \rightarrow \frac{d \tau}{d t}=\frac{R-R_{i}}{R_{i}^{2} C_{i}}+\frac{R}{R_{i} C_{i}} \phi_{\text {in }}+\frac{R}{R_{i} C_{i}}\left(\frac{1}{R_{\text {out }}}+\right.$ $\left.\frac{\zeta_{w}}{R_{w}}\right) T_{\text {out }}+\frac{R}{R_{i} C_{i}}\left(\frac{1}{R_{n}}+\frac{\zeta_{D}}{R_{D}}\right) T_{n}$

$\mathrm{ok}(\mathrm{room}) \rightarrow T_{\text {in }}=\frac{R}{R_{i}} \tau+R_{i} \phi_{\text {in }}+R\left(\frac{1}{R_{\text {out }}}+\frac{\zeta_{w}}{R_{w}}\right) T_{\text {out }}+$ $R\left(\frac{1}{R_{n}}+\frac{\zeta_{D}}{R_{D}}\right) T_{n}$

Test6 - check the performance of door-contact sensor, window-contact sensor, Toffice-wall sensor and the validity of the model (ok(room))

ok (Toffice_wall_sensor) $\rightarrow$ Toffice $=$ Toffice-wall

ok (door_contact_sensor) $\rightarrow \zeta_{D}=\tilde{\zeta}_{D}$

ok (window_contact_sensor) $\rightarrow \zeta_{W}=\tilde{\zeta}_{W}$

$\mathrm{ok}(\mathrm{room}) \rightarrow \frac{d \tau}{d t}=\frac{R-R_{i}}{R_{i}^{2} C_{i}}+\frac{R}{R_{i} C_{i}} \phi_{\text {in }}+\frac{R}{R_{i} C_{i}}\left(\frac{1}{R_{\text {out }}}+\right.$ $\left.\frac{\zeta w}{R_{w}}\right) T_{\text {out }}+\frac{R}{R_{i} C_{i}}\left(\frac{1}{R_{n}}+\frac{\zeta_{D}}{R_{D}}\right) T_{n}$

$\mathrm{ok}(\mathrm{room}) \rightarrow T_{\text {in }}=\frac{R}{R_{i}} \tau+R_{i} \phi_{\text {in }}+R\left(\frac{1}{R_{\text {out }}}+\frac{\zeta_{w}}{R_{w}}\right) T_{\text {out }}+$ $R\left(\frac{1}{R_{n}}+\frac{\zeta_{D}}{R_{D}}\right) T_{n}$

Basing on the elementary models presented in section 3, 6 tests summarized by the following signature table have been deduced. 
TABLE II: Signature Table

\begin{tabular}{|c|c|c|c|c|}
\hline & $\begin{array}{c}\text { Toffice_wall } \\
\text { sensor }\end{array}$ & $\begin{array}{c}\text { Toffice_reference } \\
\text { sensor }\end{array}$ & $\begin{array}{c}\text { Theater } \\
\text { sensor }\end{array}$ & $\begin{array}{c}\text { ROOM } \\
\text {-SYSTEM }\end{array}$ \\
\hline Test1 & 0 & 1 & 1 & 0 \\
\hline Test2 & 1 & 1 & 0 & 0 \\
\hline Test3 & 0 & 1 & 0 & 1 \\
\hline Test4 & 1 & 0 & 1 & 0 \\
\hline Test5 & 0 & 0 & 1 & 1 \\
\hline Test6 & 1 & 0 & 0 & 1 \\
\hline
\end{tabular}

Note that ROOM-SYSTEM is a macro-item which combines the non discriminable items office-door-sensor, window-door-sensor and room. It is used to reduce the number of diagnoses.

\section{Experimental VAlidation}

\section{A. Simulation scenarios}

This section demonstrates the experimental validation of the proposed diagnosis method. Tests had been performed at the entire office including all sensors. In order to make an explicit and concise explanation, the following faulty scenarios have been considered:

- scenario 1: Toffice-reference sensor is subject to bias from $\mathrm{t}=2000$ until the end of simulation.

- scenario 2: Theater sensor gives null values from $t=2000$ until the end of simulation.

- scenario 3: Door contact sensor, window contact sensor give random values from $t=2000$ until the end of simulation.

The following figures represent the results of simulation for second scenario.

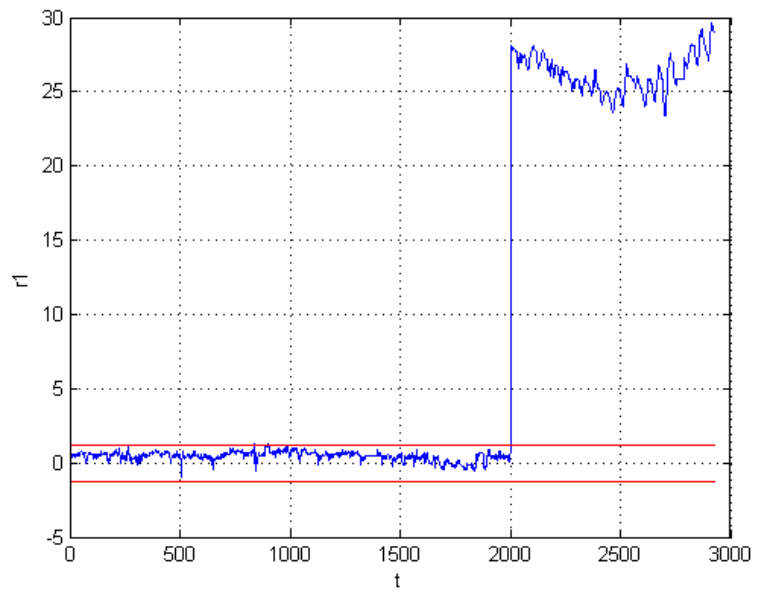

Fig. 2: Residual generation for test 1

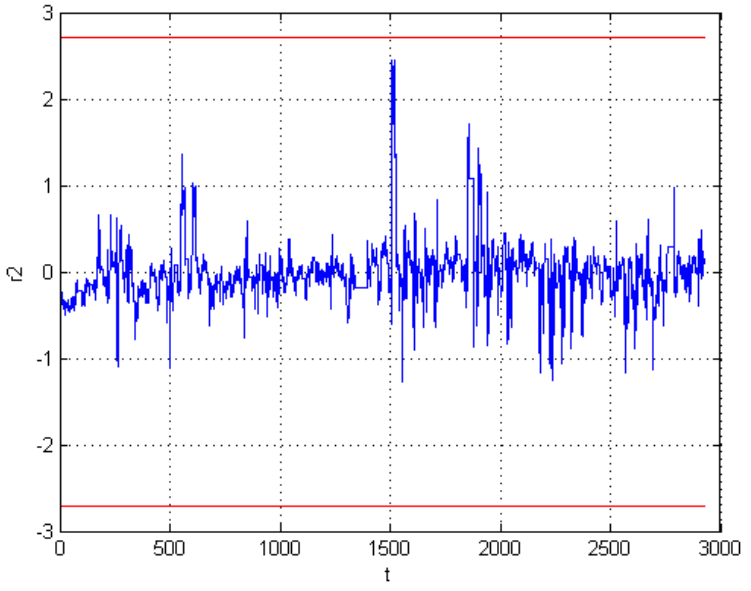

Fig. 3: Residual generation for test 2

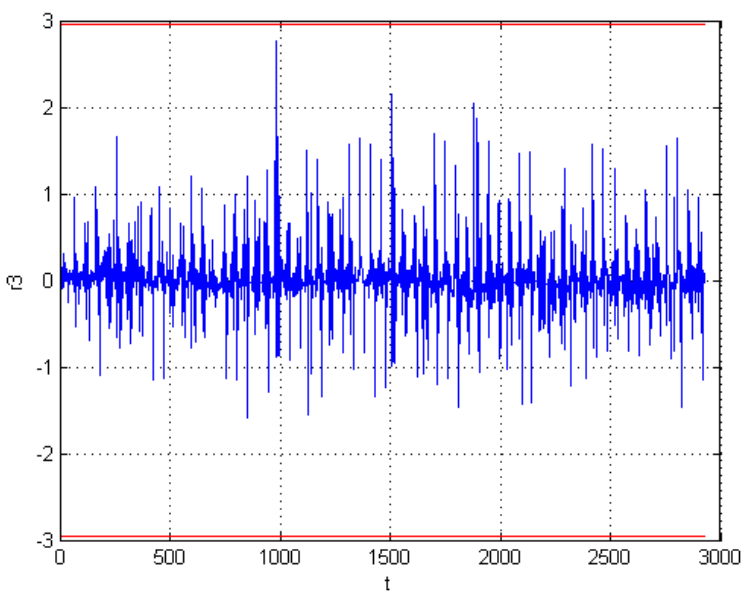

Fig. 4: Residual generation for test 3

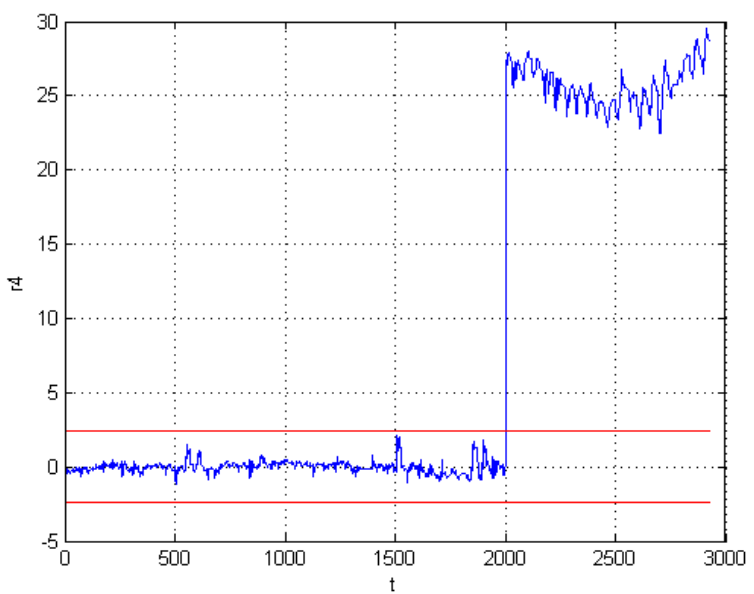

Fig. 5: Residual generation for test 4 


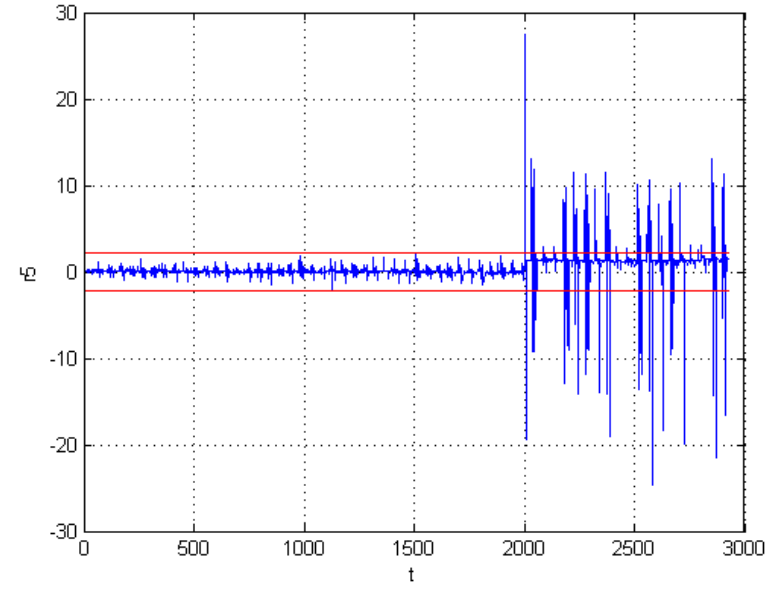

Fig. 6: Residual generation for test 5

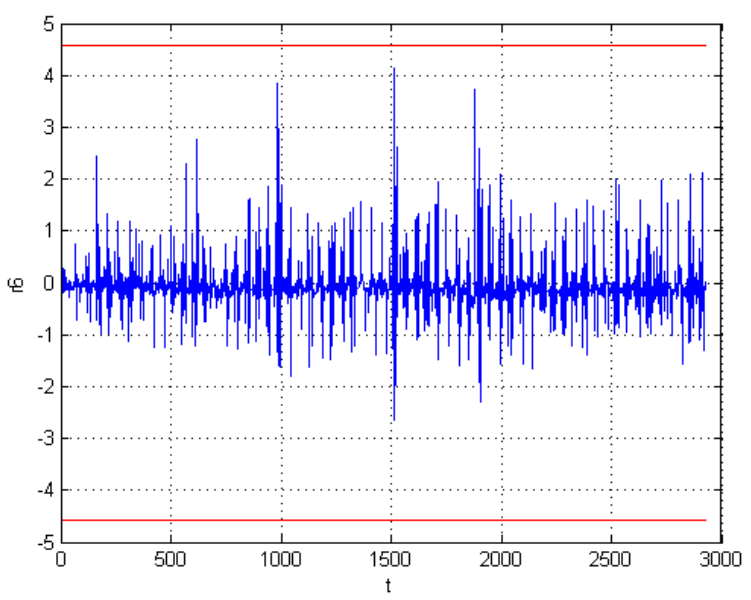

Fig. 7: Residual generation for test 6

Interpretation:

In the second scenario, we suppose that Theater sensor is faulty. The residual genaration for this scenario is described in Fig. 2, Fig. 3, Fig. 4, Fig. 5, Fig. 6 and Fig. 7.

In fact, before the appearance of fault, the signature is $(0,0,0,0,0,0)$. When the fault appears at $t=2000$, we notice that residues deviate from zero and the signature become $(1,0,0,1,1,0)$. If we compare this new signature with that at TABLE 2, we conclude that Theater sensor is faulty.

Note that only the scenario 2 is presented. Similar simulation results concerning the other scenarios are omitted for reason of space.

\section{B. Diagnosis analysis and fault isolation}

A test is defined by the following entities:

- the components that were involved in the test.

- the symptom that was observed when comparing results with expectations.

In practice, tests are performed out of the application to see how the system responds to given situations or inputs. A symptom is what the user observes when comparing the behavior of the system during a test with the results that were expected. The following values for symptoms can be obtained:

- Negative: if the system does not behave as expected, the test will be considered as failed and the symptom will be negative.

- Positive: if the system behavior is consistent with the reaction that was expected, the test is considered successful and the symptom will be positive.

Diagnoses with all kind of possible faults are found thanks to:

- Hitting Tree Set algorithm

- Hamming distance between diagnosis and effective signature

- Fault probability

The following table (Table 3) summarizes the BRIDGE possible diagnosis and actual fault for each scenario. 
TABLE III: Diagnosis result and fault explanation

\begin{tabular}{|c|c|c|c|}
\hline Scenarios & BRIDGE possible diagnosis & Actual fault & Conclusion \\
\hline Scenario 1 & $\begin{array}{l}\text { Toffice-reference }(66.66 \%) \\
\text { Theater }(66.66 \%)\end{array}$ & Toffice-reference & $\begin{array}{l}\text { Accurate } \\
\text { disgnosis }\end{array}$ \\
\hline Scenario 2 & $\begin{array}{c}\text { Theater }(100 \%) \\
\text { ROOM-SYSTEM, Toffice-wall, Toffice-reference }(50 \%)\end{array}$ & Theater & $\begin{array}{l}\text { Accurate } \\
\text { diagnosis }\end{array}$ \\
\hline Scenario 3 & $\begin{array}{c}\text { ROOM-SYSTEM } \\
\text { Toffice-wall, Theater, Toffice-reference }(50 \%)\end{array}$ & door-contact, window contact & $\begin{array}{l}\text { Not accurate } \\
\text { diagnoses }\end{array}$ \\
\hline
\end{tabular}

\section{Conclusion}

This paper presents a methodology for diagnosis of sensor grids which ensure the localization of sensor fault. Sensor faults are diagnosed using detection tests and diagnosis from first principle.

The simulation results prove that, if the tests are coherent with reality, the proposed approach leads to an accurate diagnoses. However, it is not always possible to construct tests that exactly coincide with reality. That's why, the proposed approach leads to an inaccurate diagnoses in some cases. Thus, we need additional sensors. Forming another tests can be done to prove diagnosis accuracy.

Future work will revolve around developing a diagnosis analysis system dedicated to sensor grids in the building in a multi-zone context.

\section{ACKNOWLEDGMENT}

This work was supported by the Ministry of the Higher Education and Scientific Research in Tunisia.

\section{REFERENCES}

[1] Blanke, M., Kinnaert, M., Lunze, J., Staroswiecki, M., Schröder, J. (2006). Diagnosis and Fault-Tolerant Control Springer-Verlag. Berlin Heidelberg.

[2] Chittaro, L. and Ranon, R. (2004). Hierarchical model-based diagnosis based on structural abstraction. Artificial Intelligence, 155(1-2): 147-182.

[3] Cordier, M.O., Dague, P., Dumas, M., Lévy, F., Montmain, J., Staroswiecki, M., Travé-Massuyès, L. (2000). A comparative analysis of ai and control theory approaches to model-based diagnosis. In 14th Europe an Conference on Artificial Intelligence. Berlin, Germany.

[4] Costa-Castello, R., Puig, V., Blesa, J. (2016). On Teaching Model-Based Fault Diagnosis in Engineering Curricula [Lecture Notes]. IEEE Control Systems, 36(1), 53-62.

[5] de Kleer, J., Mackworth, A. K., Reiter, R., (1992). Characterizing diagnoses and systems. Artificial Intelligence, 56 (2-3), 197-222.

[6] Goker, M. H., Howlett, R. J., Price, J. E. (2005). Case-based reasoning for diagnosis applications. The Knowledge Engineering Review, 20(3), 277-281.

[7] Khadija Tijani, Stephane Ploix, Benjamin Haas, Julie Dugdale, Dung Quoc Ngo (2016). Dynamic Bayesian Networks to simulate occupant behaviours in office buildings related to indoor air quality. In procceding IBPSA 2016 India.

[8] Mohammed, M. A., Al-Khateeb, B., Ibrahim, D. A. (2016). Case based reasoning shell frameworkas decision support tool. Indian Journal of Science and Technology, 9(42).
[9] Nicolau, A. D. S., Augusto, J. P. D. S., Schirru, R. (2017, June). Accident diagnosis system based on real-time decision tree expert system. In AIP Conference Proceedings (Vol. 1836, No. 1, p. 020017). AIP Publishing.

[10] Ploix, S., Touaf, S., Flaus, J.-M., (2003). A logical framework for isolation in fault diagnosis. In Safe Process, pp. 1-6.

[11] Pomorski, D., Perche, P. B. (2001). Inductive learning of decision trees: application to fault isolation of an induction motor. Engineering Applications of Artificial Intelligence, 14(2), 155-166.

[12] Reiter, R. (1987). A theory of diagnosis from first principles. Artificial Intelligence, 32(1), 57-95.

[13] Struss, P., 1992. What's in SD? Towards a theory of modeling for diagnosis. In Hamscher, W., Console, L., De Kleer, J.(Eds.), Readings in Model-based Diagnosis. Morgan Kaufmann Publishers Inc., San Francisco, CA, USA, pp. 419-448. 